\title{
Mikro-plastikoen iturriak eta egoera orokorra mundu mailako itsaso eta ozeanoetan
}

\author{
(Microplastic sources and overall status in worldwide seas and ocean \\ environments)
}

\author{
Amaia Mendoza*1, Juan Luis Osa ${ }^{2}$, Galder Kortaberria ${ }^{1}$, \\ Oihane C. Basurko ${ }^{3}$, Cristina Peña-Rodríguez ${ }^{1}$ \\ ${ }^{1} \ll$ Materialak + Teknologiak» Ikerketa Taldea (GMT), Ingeniaritza Kimikoa eta \\ Ingurumenaren Ingeniaritza Saila, Eskola Politeknikoa, (UPV/EHU) \\ ${ }^{2}$ Ingeniaritza Mekaniko Saila, Eskola Politeknikoa (UPV/EHU) \\ ${ }^{3}$ AZTI - Marine Research, Basque Research and Technology Alliance (BRTA)
}

\begin{abstract}
LABURPENA: Azken hamarkada arte ez gara itsas ingurumenean mikroplastikoen (MPen) presentziaz kontziente izan. MPak itsaso eta kostaldeetan metatzen diren eta $5 \mathrm{~mm}$ baino tamaina txikiagoko plastiko-partikulak dira; zenbait produktu eta aplikaziotan erabilitako plastikozko material txikiak isurtzearen edo beste objektu handiago batzuen zatikapenaren ondorioz sortzen dira. Beraien arriskuaren benetako zenbaterainokoa ezezaguna da eta mundu osoan zehar jatorria, presentzia eta eraginak ikertzen ari dira. Lan honek MPei buruz munduan zehar egin diren hainbat ikerketa-lan bildu ditu, mundu-mailan itsas konpartimentu ezberdinetan MPei dagokienez aurkitu daitekeen egoera orokorra aurkezteko helburuarekin, mugak eta ezagutze-hutsuneak azpimarratuz. Itsaso-konpartimentu guztietan topatu dira MPak: ur-azalean, sedimentuetan (itsas hondoan, hondartzetan eta kostan, oro har) eta biotan; MP kopuruak nabarmenki aldatzen delarik behatutako konpartimentuaren, neurketa-teknikaren, eremu geografikoaren eta neurketa momentuaren arabera. Ikerketak alderatzeko zailtasunak nabarmentzen dira, erabilitako metodologia ezberdinak direla medio. Hori dela eta, prozedurak bateratzeko premiazko beharra dago. Mundu-mailan gehien ekoizten diren polimero motak izaki, polipropilenoa, polietilenoa eta poliestirenoa dira MPetan gehien azaltzen direnak. Ozeanoetako MPen banaketa eta eraginaren efektuei buruzko informazioa mugatua da oraindik. Horregatik guztiagatik, egindako lana sakondu beharra dago eskala ezberdinetan (lokalean, eskualdean eta mundu mailan): metodologiak adostu, monitorizazio-programak ezarri, iturriak hausnartu, MP sekundarioen degradazio-mekanismoetan sakondu, eta konpartimentuen arteko dinamikak eta ingurumenaren zein giza osasunaren gaineko eraginak aztertu.
\end{abstract}

HITZ GAKOAK: mikroplastikoak, berrikusketa, itsasoa, presentzia, konpartimentuak.

ABSTRACT: Until recent years we have been unaware of the presence of microplastics (MPs) in the marine environment. MPs are plastic particles smaller than $5 \mathrm{~mm}$ accumulated in seas and shores, due to the dumping of small plastic materials used in certain products, or by the fragmentation of larger plastic objects. The actual extent of their risk is yet unknown and their origin, occurrence and impacts are being investigated. This work has included a number of researches on MPs worldwide, with the aim of presenting a global situation on the topic, emphasizing the limits and knowledge barriers. MPs are found in all marine compartments: on the water surface, in sediments (at the seabed and beaches) and in biota. MPs abundance vary significantly depending on the compartment, the measurement methodology, the geographic area and even on the sampling period. Difficulties are found when comparing researches, as different methodologies are being used. For this reason, there is an urgent need to standardize procedures. Polypropylene, polyethylene and polystyrene are the most common materials in MPs, in agreement with the most commonly used plastic materials in the world. The information on the distribution and impacts of MPs in the oceans is still limited. For this reason, research on the topic must be deepened at different scales (locally, regionally and globally) with the aim to: agree methodologies, set monitoring programmes, assess sources, deepen on the degradation paths of secondary MPs, and analyse the impacts on environmental and human health.

KEYWORDS: Microplastics, review, sea, occurrence, compartments.

* Harremanetan jartzeko / Corresponding author: Cristina Peña-Rodríguez, Materialak + Teknologiak Ikerketa Taldea (GMT), Ingeniaritza Kimikoa eta Ingurumenaren Ingeniaritza Saila, Eskola Politeknikoa, Euskal Herriko Unibertsitatea (UPV/EHU), Europa Plaza, 1, 20018 Donostia-San Sebastián. Euskal Herria. - cristina.pr@ehu.eus - https://orcid.org/0000-0001-7553-2093.

Nola aipatu / How to cite: Mendoza, Amaia; Osa, Juan Luis; Kortaberria, Galder; Peña-Rodríguez, Cristina; Basurko, Oihane C. (2020). «Mikro-plastikoen iturriak eta egoera orokorra mundu mailako itsaso eta ozeanoetan»; Ekaia, ale berezia 2020, 233-251. (https://doi.org/10.1387/ekaia.21038).

Jasoa: 26 uztaila, 2019; Onartua: 12 abendua, 2019

ISSN 0214-9001 - elSSN 2444-3255 / (c) 2020 UPV/EHU

(c) (i) Obra hau Creative Commons Atribución 4.0 Internacional-en

lizentziapean dago 
Amaia Mendoza, Juan Luis Osa, Galder Kortaberria, Oihane C. Basurko, Cristina Peña-Rodríguez.

\section{SARRERA}

Plastikoaren erabilera 1950eko hamarkadaz geroztik zabalki hedatua dago mundu-mailan paketatze-, automobilgintza-, eraikuntza-, elektronika- zein nekazaritza-arloetan [1]. Ordutik, material horren eskaera nabarmen igo da [2], haren abantaila ugariak direla eta: dentsitate baxua eta arintasuna, korrosioarekiko erresistentzia, iraunkortasuna eta xaflakortasuna, moldagarritasuna eta kostu baxua. Halaber, plastikoen kantitate handi bat erabilera bakarreko aplikazioetarako ekoizten da; ondoren, epe laburrean hondakin izatera pasatzen da. Europan, erabilera bakarreko plastiko horiek 2019/904 Zuzentarauak [3] arautu berri ditu, zenbait produktu plastikok ingurumenean duten inpaktua murrizteko. Material plastikoen ekoizpen eta erabileraren hazkundearen ondorioz, mundu osoan sortutako plastikoen hondakinen kopuruak nabarmen gora egin du azken hamarkadetan. Kudeaketa desegokiak eragiten du sortzen diren hondakin horien frakzio garrantzitsu batek ingurumenean aske amaitzea. Hain zuzen ere, itsasoak eta ozeanoak hondakinen frakzio handi baten helmuga dira, ur kontinentalen drainatze-norabidean maila baxuena baitira, eta gutxi gorabehera munduko biztanleriaren erdia kostaldeetako lehen $60 \mathrm{~km}$-etan kontzentratzen baita [4]. Lurreko jatorriaz gain, itsasoko jarduerak ere ozeanoetara jaurtitako hondakinen iturri garrantzitsua dira [2,4]. Material sintetiko horiek naturalki oso gutxi eta astiro degradatzen direnez, itsas ingurumena ez da hondakin sarrera antropiko horiek kudeatzeko gai, eta egun, ondorio ezezagunak dituen erritmoan metatzen ari dira.

Plastikozko hondakinak itsasoan neurriaren arabera, makroplastiko (2,5 $\mathrm{cm}$ baino handiagokoak), mesoplastiko ( $5 \mathrm{~mm}$ eta $2,5 \mathrm{~cm}$ bitartekoak) eta mikroplastiko (MPak) edo nano eta mikroplastiko gisa (NMPak) $(5 \mathrm{~mm}$ baino txikiagokoak) sailkatu ohi dira [5]. Hala ere, ikerketa-literaturan definizio ugari aurki daitezke mikroplastikoei buruz, tamainaren arabera; horrek arazo bat dakar datuak konparatzeko garaian. 2008. urtean, Estatu Batuetako Nazioko Ozeanografia eta Atmosferako Agentziak (NOAA) definizio bat proposatu zuen MPentzat, eta izen hori $5 \mathrm{~mm}$ baino diametro txikiagoa dutenei eman zien[6], tamainaren arabera biotak irensteko probabilitatean oinarrituta [2]. Gaur egun, hori da lan gehienetan onartzen den definizioa [7], Europako Batasuneko Itsas Estrategiaren Zuzentarauak (MSFD) [8] barne. Modu berean, Frias eta lankideek [9], Europan MPen monitorizazioa estandarizatzeko BASEMAN proiektua dela medio, MPak definitzen dituzte: uretan disolbaezina den edozein partikula sintetiko, solido edo matrize polimeriko, forma erregular edo irregularreko, 1 um eta $5 \mathrm{~mm}$ arteko tamainakoa eta jatorri primario edo sekundarioa duena. Hala ere, oraindik ez dago batere argi zein izan behar den tamaina minimoa MPen definizioan. Hain zuzen ere, azken urteotan, ikerketak tamaina nanometrikora ere hedatu dira, eta «nano eta mikroplastiko» (NMPs) kontzeptua sortu [5]. 
Itsasoetan azaltzen duten nonahikotasunaz gain [10-13], haren tamaina txikia dela eta elikadura katean sar daitezkeenez [5, 14, 15], MPek interes eta kezka handia sortu dute azken urteotan. Hori dela eta, ikerketa zabaltzea beharrezkoa da, MPen iturriak, helmuga eta efektuak eskala ezberdinetan aztertzeko. Horrela, 2008an onartutako Europako Batasuneko Itsas Estrategiaren Zuzentarauak (MSFD) [8] estatu kideak behartzen ditu kostaldeko, ur gainazaleko eta itsas hondoko sedimentuetako mikrohondakinen konposizioaren, zenbatekoaren eta banaketa espazialaren berri ematera, horiek kostaldeko eta itsas ingurunean kalte egiten ez duten mailetan daudela ziurtarazteko. Testuinguru honetan, berrikusketa-lan honek MPei buruz munduan zehar egin diren hainbat ikerketa-, jatorri-, dinamika- eta modelizazio-lan bildu ditu. Mundu-mailan itsas konpartimentu ezberdine$\tan$ MPei dagokienez aurkitu daitekeen egoera orokorra aurkeztea du helburu ekarpen honek, gaiari buruzko mugak eta ezagutze hutsuneak azpimarratuz.

\section{TESTUINGURUA}

Material plastikoak jatorri fosil edo biologikoko egitura organiko makromolekularra duten polimeroak dira. Nahiz eta familia handia osatzen duten, sei plastiko nagusik menperatzen dute merkatua: polietilenoa (PE, dentsitate handi eta txikikoa), polipropilenoa (PP), binilo polikloruroa (PVC), poliestirenoa (PS, PS-E poliestireno hedatua barne), poliuretanoa (PUR) eta polietilen tereftalatoa (PET) [2].

2017. urtean, Europako plastiko eskakizunaren \% 39,7 paketatze-industriatik etorri zen; bigarren postuan, eraikuntza azaltzen zen (\% 19,8).

Eskakizun handiena izan zuten materialak PE (filmak, jostailuak, edukiontziak, hodiak, e.a.) $(\% 29,8)$ eta PP (elikagaien bilgarriak, edukiontziak, hodiak, autoen piezak, e.a.) (19,3\%) izan ziren [1]. 2017. urtean (1. irudia), 348 milioi tona plastiko ekoitzi ziren munduan $(64,4$ milioi tona Europan); Txina zen ekoizle nagusia (\% 29,4) [1]. UNEParen (United Nations Environment Programme) arabera [4], joerak jarraitzen badu, plastiko-ekoizpena 2.000 milioi tonara irits daiteke 2050 . urterako.

Material honen zati batek ingurunean bukatzen du, batez ere itsasoan, nahita edo halabeharrez, hondakinen kudeaketa ezegokia, gizakiaren portaera arduragabea edo halabeharrezko galerak direla medio. Horrela, itsasoko zaborraren \% 80-85 plastikoek osatzen dute [17]. Itsaso eta ozeanoek lehorreko jardueretatik etorritako plastikoen zeharkako sarrerak jasaten dituzte ibai eta haizeen bitartez (\% 80-86), baita zuzeneko sarrerak ere, itsasoko jardueretatik (\% 14-20) [18-20]. Beste ikerketa batzuen arabera, $200 \mathrm{~mm}$ baino handiagoko makrohondakin flotatzaileen masaren $\%$ 70ek 
arrantzan izango luke jatorria, batez ere buia eta kulubizetatik [21]. Jambeck eta lankideek [22] 2010. urtean, 275 milioi tona plastiko ekoitzi zirela estimatu zuten munduko 192 herrialde kostaldedunetan; horietatik, 4,8 eta 12,7 milioi tona artean itsasora galdu lirakete, hau da, urte horretako ekoizpen globalaren \% 1,7-4,6. Thompsonen estimazioen arabera [23] ekoitziriko plastikoen hamarren batek ozeanoetan amaitzen du. Are gehiago, Schmidt eta lankideek [24] estimaturikoaren arabera, 0,41-4 milioi tona plastiko itsasoratzen dira urtero ibaien bitartez. 1. taulan, itsasoan aurkituriko plastiko mota nagusiak azaltzen dira taldeka; horien artean, munduko plastiko merkatua menperatzen duten mota nagusiak ikus daitezke (HDPE, LDPE, PP, PVC, PS, PUR eta PET).

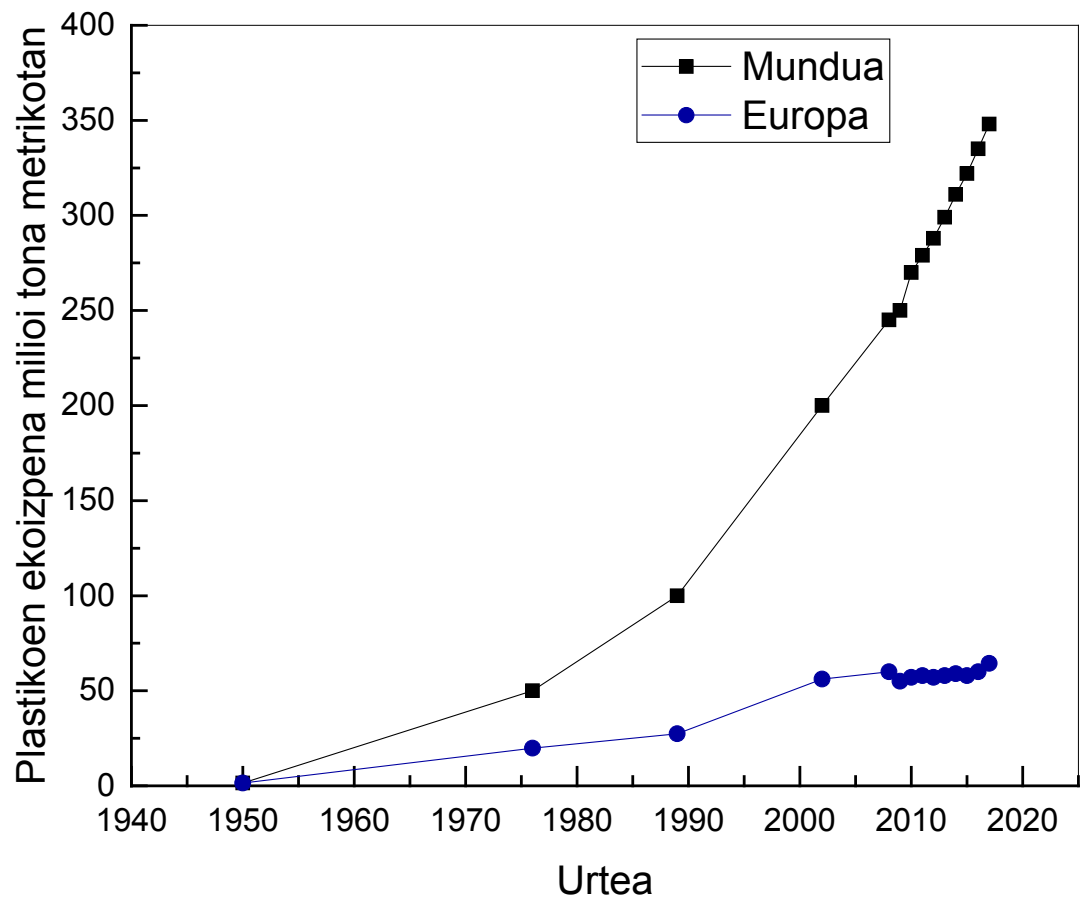

1. irudia. Mundu mailako plastiko-ekoizpena 1950 eta 2017 bitartean (milioika tonatan) $[1,16]$.

Plastikoen degradazio naturalaren abiadura bereziki motelak eta dentsitate baxuak haizearen edo uraren bitartezko dispertsioa ahalbidetzen du; sorlekutik milaka kilometrora heda daitezke, baita munduko urrutiko aldeetara ere $[10,11]$. 
1. taula. Polimero mota desberdinen agerpen-maiztasuna ikerketetan*, mundu-mailako itsaso edo itsas sedimentuetan lagindutako MPetan (Hidalgo-Ruz eta lankideak, 2012tik moldatua [25]). *42 ikerketen arabera.

\begin{tabular}{lc}
\hline \multicolumn{1}{c}{ Polimero mota } & $\begin{array}{c}\text { Ikerketak mundu mailan } \\
(\%)\end{array}$ \\
\hline Polietilenoa (PE) & 79 \\
Polipropilenoa (PP) & 64 \\
Poliestirenoa (PS) & 40 \\
Poliamida (nylon) (PA) & 17 \\
Poliesterra (PES) & 10 \\
$\quad$ Polietilen tereftalatua (PET) & 2 \\
$\quad$ Alkidikoa (AKD) & 2 \\
Akrilikoa & 10 \\
$\quad$ Poli metilakrilatoa (PMA) & 5 \\
Polioximetilenoa (POM) & 10 \\
Polibinil alkohola (PVA) & 7 \\
Polibinil kloruroa (PVC) & 5 \\
Poliuretanoa (PU) & 2 \\
\hline
\end{tabular}

\section{MIKROPLASTIKOAK}

\subsection{Definizioa}

Ozeanoetan itsas hondakin gisa azaltzen diren mikropartikula gehienak MPei dagozkie, nahiz eta badiren itsasoko ingurunera etengabe iristen diren beste mikopartikula batzuk ere, hala nola errekuntza-gasen errautsak edo partikula metalikoak [26]. Nahiz eta makroplastiko erako hondakinak izan diren azken urteetako ingurumenarekiko kezka nagusia, mende honen hasieratik, mikropartikulak kutsadura-eragile nabarmen izatera iritsi dira [27]. Plastikozko objektu handiak erraz ikusten dira eta inpaktu sozial, ekonomiko eta ekologiko nabarmenak dakartzate: itsas animaliak arrantzasareetan kateatzen dira, zaborra azaltzen da kostaldeko alde turistikoetan edo ontzien uraren bitartezko hozte-sistemak blokeatzen dira. Plastikozko objektu txikiagoak ez dira hain begi-bistakoak eta haien inpaktu potentzialak ez dira hain nabariak. Dena den, 1970eko hamarkadan, lehen aldiz publikatu zen literatura zientifikoan ozeanoetako plastikozko objektu txikiei buruz [28], objektu horiek organismoek irensteak izan zitzakeen ondorioak aipatuz. Gai hau alde batera utzia izan da erkidego zientifikoaren zein ezzientifikoaren aldetik urte askotan zehar ordea [2], Thompson eta lankideek [27] beren ikerketa argitaratu arte, non «mikroplastiko» hitza lehen aldiz azaldu baitzuten. Ordutik, MPen presentziak eta gizaki zein anima- 
lien osasunean izan ditzaketen eraginek arreta publiko zein zientifiko handiagoa jaso dute [26], eta argitalpen kopurua ia modu esponentzialean handitu da (2. irudia).

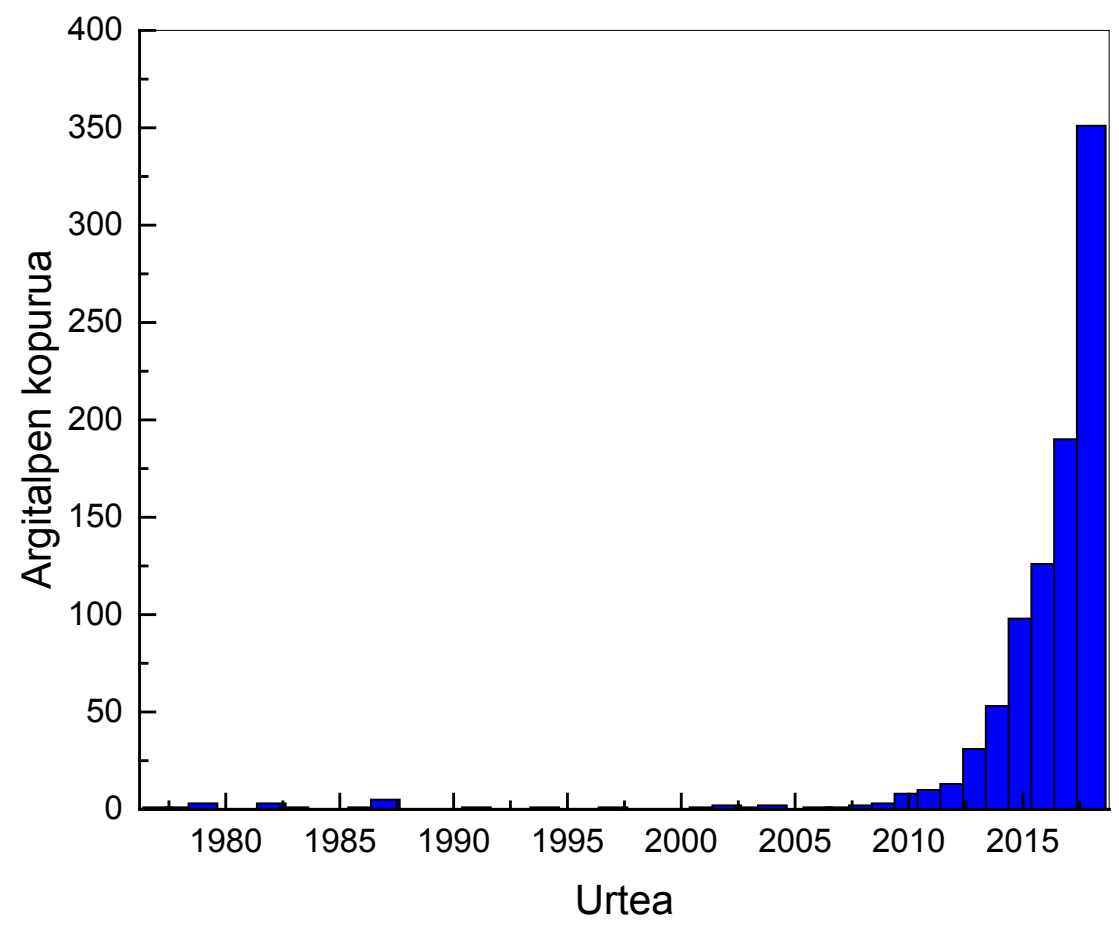

2. irudia. Urteko publikazio kopurua, 1977 eta 2018 bitartean, honako terminoen bilaketen konbinazioetan oinarriturik: «mikroplastikoak»/«pellet plastikoak»/《zuntz plastikoak» eta «itsaso»/《ozeano»/<hondartza»/<kostalde» (Scopus, 2019. urteko otsaila).

MPekiko interes berrituak argi azaldu du kutsadura-eragile horiek itsas ingurunean erabat hedaturik daudela [29]. Azken hamarkadetan, MPen ugaritasuna eta ozeanoetan azaltzen duten banaketa globala etengabe handitu direla aurkitu da [7, 29], haien tamainaren txikitze nabarmenarekin batera [11].

\subsection{Sailkapena}

MPek talde heterogeneoa osatzen dute: tamaina, forma, kolorea, konposizio kimikoa, dentsitatea eta beste zenbait ezaugarri izan ditzakete. Jatorriaren arabera, (i) MP 'primarioak', produktu eta aplikazio industrialetan zuzen erabiltzeko sortuak, zein (ii) MP 'sekundarioak', objektu 
handiagoen zatitzetik eratorriak, izan daitezke [29]. Primario eta sekundarioen arteko bereizte horrek iturri potentzialak identifikatzen laguntzen du, eta bai ingurumenera iristen den kopuruaren txikitzera bideraturiko neurriak hartzen.

MP primarioen artean, gainazalak garbitzeko urratzaile industrialak, produktu kosmetikoetako mikroesferak edo prozesu industrial ugaritan erabilitako nanopartikula plastikoak aipa daitezke. Gainera, produktu plastikoen ekoizpenean erabiltzen diren erretxina gordinen granulu eta hautsak ere talde honetan sar daitezke. MP primarioak ibai edo hondakin-uren bitartez iristen dira itsasoetara, ur-hondakinen tratamendurako prozedurek ezin baitituzte modu eraginkorrean ezabatu [30, 31].

MP sekundarioak objektu plastiko handiagoen zatitzetik sortzen dira. Zatikatze hori zenbait produkturen erabileran gerta daiteke, hala nola ehungaietan, gurpil edo margoetan, edota behin produktu horiek ingurumenera botatzen direnean. Adibidez, arropa-garbiketa da itsasoetan bukatzen duten mikrozuntz gehienen iturria [7, 32,33]. Bestalde, itsasoetan aurkitzen diren objektu plastiko handienak, hauskor bihurtzen dira beroaren eta erradiazio ultramorearen eraginez, eta zatikatu egiten dira haize eta olatuen eraginaren ondorioz [34]. Beraz, makrohondakina MP iturri garrantzitsua dela esan daiteke $[19,35]$. Honakoak dira molekula polimerikoen degradazioa edo deskonposaketa kimikoa sortzen duten eragile nagusiak [34]: a) eguzki-izpien bitartezko fotodegradazio-erreakzioak, b) erreakzio termikoak, termooxidazioa barne, c) polimeroen hidrolisia, d) mikrobio bitartezko biodegradazioa. Hala ere, ez da degradazio berdina gertatzen eguzkiaren erradiazioaren eta beroaren eraginpean dauden plastikoetan edo uretan aurkitzen diren haietan, uraren tenperatura baxuak prozesua nabarmen atzeratzen baitu. Ur-zutabean hondoratzen diren hondakin plastikoen kasuan, erradiazio ultramorearen gabeziak (itsasoko urak nabarmen moteltzen baitu), tenperatura baxuek eta oxigenoaren kontzentrazio txikiagoak eragiten dute degradazioa nabarmenki txikiagoa izatea ur azalean flotatzen dauden plastikoena baino. Horrela, itsasoko ingurunean MPak sortzeko tokirik aproposenak hondartzak dira [19]. Itsaso ingurunean plastiko mota ezberdinen degradazio-prozesuak aztertzen ari dira ikerketa berrietan [36-39]. Adibide batzuk aipatzeko asmoz, zenbait autoreren lana azpimarra daiteke. Horrela, Kedzierski eta lankideek [36] aurkitu dute, lehen aldiz, konposatu estrogenikoen isurketa, zitotoxikoak ez diren PVC edo poli(butilen adipatoco-tereftalato) (PBAT) polimeroen itsas inguruneko degradazioan. Lambert eta lankideek [37], bestalde, frogatu dute PS edo poli(azido laktiko) (PLA) bezalako polimeroen degradazioan horien nanopartikulak isurtzen direla; tamaina desberdinekoak polimeroaren arabera. Itsas inguruneko degradazio urratzaileari UV izpien efektua gehitzen zaiela azpimarratu dute Song eta lankideek [39], PS, PP, PE eta horien gisako plastikoen degradazioa aztertzerakoan; lorturiko partikulen tamainak polimero motaren araberakoak 
dira. Polimero mota desberdinen portaerak eta ingurumeneko baldintzen efektuek eskatzen dute sorturiko degradazio-prozesuak sakon aztertzea kasu bakoitzean; geroz eta ikertzaile gehiago dabiltza lan horretan.

2. taula. MPak haren itxuraren arabera sailkatzeko erabilitako kategoriak [40].

\begin{tabular}{c|c}
\hline \multirow{4}{*}{ Mota } & Plastiko zatiak \\
Pelletak \\
Filamentuak \\
Plastiko filmak \\
& \multicolumn{1}{c}{ Plastiko bitsak } \\
Granuluak \\
Poliestireno bitsak
\end{tabular}


MPen karakterizazioan erabiltzen diren beste sailkapen batzuek forma, tamaina edo kolorea izaten dute kontutan, itsas hondakinen monitorizaziorako Europar gidalerroak proposaturikoak bezala [40] (2. taula). Ezaugarri horiek MPen iturri potentzialei buruzko informazioa ematen dute, eta bai itsasoko bizidunengan sortzen duten erakarpen- eta irenste-probabilitateari buruzko informazioa ere. Horren adibide gisa, filamentu-formako MPak kasu askotan zuntzetatik datozela ikusi da [32], eta itsas hondoetan mota honetako MP ugari aurkitzen ari dira [12,13]. Bestalde, pelletak polimero desberdinetako erretxina birjinak dira, plastikozko produktuen konformazioaren aurretik prozesuan galdutako lehengaiak, alegia. Granulu-formako MPak produktu desberdinetan erabilitako MP primarioekin erlaziona daitezke [4]. Koloreak ere garrantzia duela frogatu da bizidunen erakarpenari dagokionez: kolore zuriko MPek irensteko erakartasun handiagoa eragingo lukete zenbait arrainengan, beren ohiko harrapakinekin nahasten dituztelako [41].

\subsection{Iturriak, helmugak eta ondorioak}

Sherringtonek [20] estimatzen du urtean ozeanoetara iristen diren plastikoen \% 78 lehorreko aktibitatetatik datorrela makroplastiko moduan; \% 8, jatorri primarioa duten MPetatik, eta \% 14, itsas aktibitateetatik. MPen itsas inguruneko banaketa dentsitatearen mendekoa da. Hidalgo-Ruz eta lankideek [25] baturiko datuen arabera, itsasoko urak baino dentsitate txikiagoa duten MPek ur-azalean flotatu egiten dute $\left(0,022-8,654\right.$ item $_{\mathrm{MP}} / \mathrm{m}^{3}$, non item hitzak MP unitateak azaltzen dituen); ur-azaltzat itsasoko lehen 10-20 cm-ko geruza hartzen da [42, 43]. Baina MPak ur-zutabean suspenditurik ere azaltzen dira $\left(0,014-12,51\right.$ item $_{\mathrm{MP}} /$ $\left.\mathrm{m}^{3}\right)$. Ur azpiko sedimentuak MPentzat estolda-zuloa direla esan daiteke $[12,13,20]\left(18.000-125.000\right.$ item $\left._{\mathrm{MP}} / \mathrm{m}^{3}\right)$. Hondartzetan, aldiz, tarteko inguruneak direnak bai flotatzen duten partikulak bai sedimentatuak biltzen dira $\left(185-80,000\right.$ item $\left._{\mathrm{MP}} / \mathrm{m}^{3}\right)$ [25].

Oro har, MPak ez dira makroplastikoak bezala mugitzen ozeanoetan: makroplastikoen banaketa espaziala korrontearen eta haizearen arabera azaldu daiteke; MPen banaketa eragiten duten mekanismoak, aldiz, ez dira hain ezagunak: partikulen agregazioak edo biotaren aktibitateak eragina izan dezakete. Horrela, MPek itsasoan mikroorganismoz osatutako biofilma sortzeko joera dute; horrek partikularen dentsitate espezifikoa handitzea eta, beraz, hondoratzea eragiten du. Aitzitik, higadurak dentsitate espezifikoaren gutxitzea eragin dezake eta, ondorioz, gainazalaren, ur-zutabearen eta itsas hondoaren arteko MP-transferentzia aldakorra izan daiteke [25]. Van Sebille eta lankideek [44] estimatu zuten, 2014. urtean ozeanoen gainazalean metatutako MP kopurua 15 eta 51 trilioi partikula artean zegoela, 93 eta 236 mila milioi tonako pisuarekin; kopuru handiena Ipar Pazifikoan zen (3. taula, 3. irudia). 
3. taula. MPen kontzentrazio eta banaketa munduan zeharreko ozeano-azalean, Maximenko eta lankideak[45], Lebreton eta lankideak [46] eta van Sebilleeta lankideak [44] ikertzaileen ereduen arabera, van Sebille eta lankideetatik [44] egokituta.

\begin{tabular}{lcc}
\hline \multicolumn{1}{c}{ Ozeano arroa } & $\begin{array}{c}\text { MPen kontzentrazio tarteak, } \\
\text { ereduen arabera } \\
\left(10^{12} \text { item }_{\mathrm{MP}} / \text { ozeano arroko }\right)\end{array}$ & $\begin{array}{c}\text { MPen kontzentrazio tarteak, } \\
\text { ereduen arabera } \\
(\mathrm{t} / \text { /ozeano arroko })\end{array}$ \\
\hline Ipar Pazifikoa & $7,3-15,9$ & $62.800-155.200$ \\
Hego Pazifikoa & $0,3-0,8$ & $1.000-3.700$ \\
Ipar Atlantikoa & $0,3-1,3$ & $3.600-17.700$ \\
Hego Atlantikoa & $1,0-2,6$ & $6.200-15.500$ \\
Indiako Ozeanoa & $2,0-3,0$ & $5.500-15.000$ \\
Mediterraneoa & $3,2-28,2$ & $4.800-30.300$ \\
\hline GUZTIRA & $14,9-51,2$ & $93.300-236.000$ \\
\hline
\end{tabular}
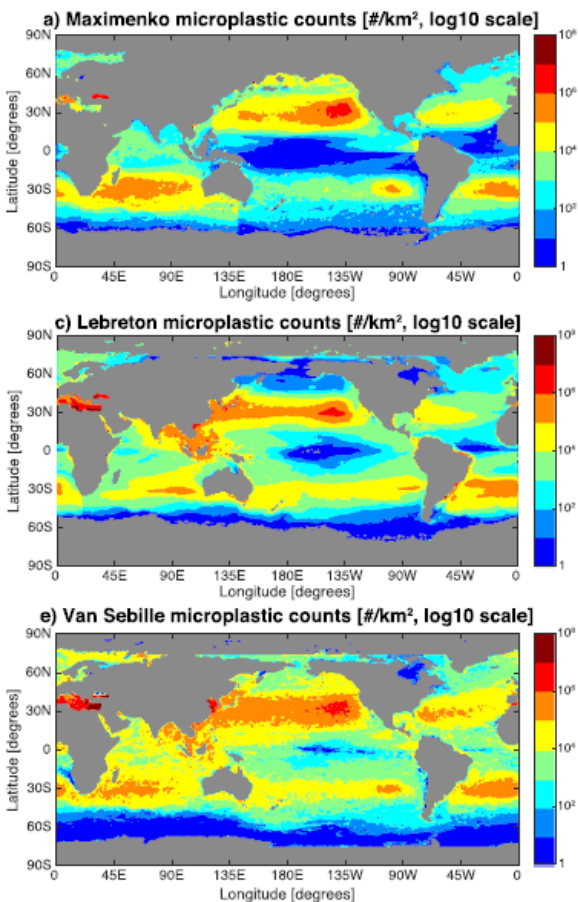
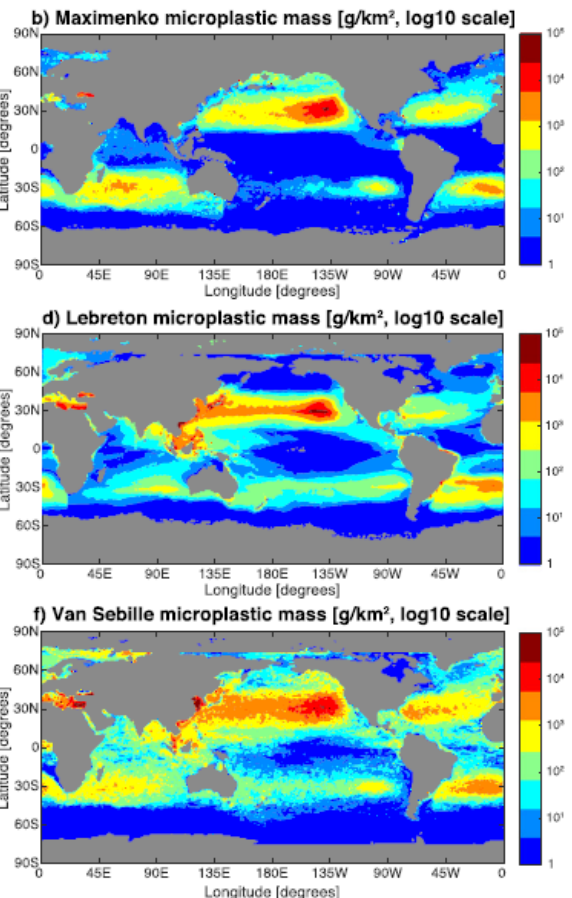

(Reproduced from van Sebille et al., 2015. (C) IOP Publishing Ltd. CC BY 3.0.)

3. irudia. MPen dentsitatearen ozeano azaleretako mapak, van Sebille eta lankideen [44] ereduaren arabera. 
Tamaina txikiagoa dela eta, MPak errazago irents ditzakete organismo ezberdinek, eta elikadura katean sar daitezke. Ebidentziak dio itsas biotak (hegaztiak, arrainak, dortokak, ugaztunak eta ornogabeak barne) MPekin elkarreragiten duela, eta transferentzia trofikoa dagoela harrapakari eta harrapakinen artean [14]. Eragin biologikoak MPen tamainaren araberakoak dira. Tamaina handienak erraz irensten eta jaurtitzen dira; txikienek organismoetan zelularki eragina lukete. Hala eta guztiz ere, oraindik ez dira ondo ulertzen MPek populazio naturaletan eta elikagaien sareetan izan ditzaketen ondorioak, eta itsasoko organismoen inguruko ikerketa gehiago egin beharra dago MPek ingurumenean dituzten inplikazioak zehatzago ulertzeko. Bestalde, haien konposizioak eta azaltzen duten azalera espezifiko erlatiboki altuak egoki egiten dituzte uretan kutsatzaile organikoak (POP, Persistent Organic Pollutant) gehitzeko eta toxikoak diren plastikoen gehigarriak (egonkortzaileak, plastifikatzaileak, e.a.) lixibiatzeko [47]. Beraz, MPen irensketak toxinak sar ditzake elikadura katearen oinarrian, zeinetatik biopilaketa etor daitekeen [48]. Hori guztia dela eta, FAO, UNESCO-IOC, UN, UNEP eta Europako Komisioa eta gisako nazioarteko erakundeak MPen kopurua, iturriak, helmuga eta ingurumenean eta gizakien osasunean izan ditzaketen ondorioak aztertzeko ikerketa gogor ari dira bultzatzen.

\section{MIKROPLASTIKOAK MUNDUAN ZEHAR}

Hainbat ikerketa garatu dira munduan zehar itsaso eta ozeanotan [14]. Hala ere, ozeanoetako MPen banaketa eta eraginaren efektuei buruzko informazioa mugatua da oraindik. MPen presentzia itsas ingurune konpartimentu bakoitzarentzat izan da ebaluatua, hala nola itsasoko uretan, hala azaleran [25, 32] nola ur-zutabean [49], itsas hondoan [12, 13], hondartzetako sedimentuetan [32], biotan [14], eta baita ur gezaren iturrietan, ibai, laku edo izotz polarretan ere [21, 29, 50, 51]. Gaur egun, ikerketa horiek osatzen ari dira MPen lurreko presentzia ere aztertuz, hondakin-uren araztegietan sorturiko lohiak laborantzan ongarri bezala edo lurraren betegarri bezala erabiltzeak iturri berriak sortzen baititu [52]. Ingurumen-konpartimentu horiek guztiak elkarrekin erlazionatuak daude ur ziklo eta korronteen bitartez, MPak batzuetatik besteetara mugitzea ahalbidetuz.

Ozeanoetako MPen miaketen helburua konpartimentu-unitate bakoitzeko egon daitekeen MP kopurua kuantifikatzea da. Konpartimentu-unitatea konpartimentuen ezaugarrien araberakoa da; erabilienak honakoak dira: item $\mathrm{MP}_{\mathrm{MP}} / \mathrm{km}^{2}$ azalerako urentzat, item $\mathrm{MP}_{\mathrm{MP}} / \mathrm{m}^{3}$ azpiazalerako urentzat, item $_{\mathrm{MP}} / 50 \mathrm{ml}$ edo item $\mathrm{MP}_{\mathrm{MP}} / \mathrm{kg}_{\mathrm{DW}}$ (MP item kilogramo pisu lehor bakoitzeko) itsas hondoko edo hondartzetako sedimentuentzat eta item $\mathrm{MP}_{\mathrm{P}} / \mathrm{g}_{\mathrm{WW}}$ (MP item gramo pisu heze bakoitzeko) edo item $\mathrm{MP}_{\mathrm{M}}$ indibiduo biotarentzat. MPak zenbatzeaz gain, ikerketa batzuek konpartimentu-unitateko MPen pi- 
su-frakzioa ere ematen dute, informazio gehigarri bezala. Laginak batzeko metodologia konpartimentuen ezaugarrietara moldatzen da (itsasoko ura, hondarra edo lokatza duen materia, eta biota) [40]. Prozedura laginen bilketarekin hasten da (sareen arrastea ur-gainazalean, ponpaketa ur-zutabean, bilketa zuzena hondartzetako sedimentuetan). Ondoren, MPak banantzen dira laginetatik honako prozeduraren bitartez: lehenik, baheketa egiten da, begi desberdineko zetabeak erabiliz laginak tamaina-tarteetan banatuz; ondoren, dentsitate-desberdintasuna aprobetxatuz, flotazioz banatzen dira laginak, dentsitate baxueneko partikulak bereiziz; eta bukatzeko, behaketa handipen luparekin egiten da MPak bisualki bereizteko, sailkapena ahalik eta zehatzena izan dadin. Kasu batzuetan, biofilma kendu behar zaio laginari MPen konposizioa aztertzeko. Normalean, kontaketa behaketaz egiten da, banaka, MPen tamaina eta morfologia aztertzeko. Kontaketa-prozesua zaila eta luzea izan ohi da. Beraz, laginak jasotzeko metodologiekin batera, kontaketa-prozesuak ere estandarizatu beharra dago. Azkenik, ikerketa batzuek polimero mota ere aztertzen dute, batez ere Raman edo FTIR espektroskopien bitartez. Raman espektroskopia argi monokromatikoaren dispertsio inelastikoan oinarrituriko teknika espektroskopikoa da. Argi monokromatiko hori laser bat izan ohi da. Laser-argia fonoiekin edo sistemako beste eszitazio batzuekin interakzioan aritzean, laserraren fotoien energian aldaketak sortzen dira. Desplazamendu energetikoak molekularen modu bibrazionalei buruzko informazioa ematen du; laginean azaltzen diren molekula edo talde funtzionalak identifika daitezke. FTIR espektroskopia edo espektroskopia infragorria ere antzeko teknika da, molekulen bibrazio-mailekin lotuta dago. Maila horien arteko eszitazioak eragiteko, argi infragorriaren energia beharrezkoa da. Espektroskopia infragorriak erradiazio infragorriak materiarekin duen interakzioa azaltzen du; horren talde funtzional desberdinek maiztasun konkretuetan bibratzen dute, espektroaren alde desberdinetan azalduz eta identifikazioa ahalbidetuz. Bigarren teknika horrek lehengoarekiko abantaila nagusi bat eskaintzen du, laginak pasatu ahala identifika baititzake (on line); horrela, banaketa asko errazten da. Oso ohikoa da gaur egun FTIR espektroskopiaren erabilera hondakin plastikoen taldekako banaketa egiteko [53].

Emaitzak asko aldatzen dira lagindutako konpartimentuaren arabera, eta baita erabilitako bilketa motaren eta analisi-metodologiaren arabera ere; alde geografikoak eta bilketa egin den garaiak ere eragin handia dute. Metodologia estandarizatuen gabeziak ikerketa ezberdinen arteko konparaketa oztopatzen du [14].

Ozeanoetako azaleraren kasuan, ozeanoetako MPen banaketa modelizatu da, mundu osoko eremu desberdinetan monitorizaturiko datuetatik abiatuta [44-46]; kopuru handienak Mediterraneo eta Ipar Pazifikoan aurkitu dira (3. taula, 3. irudia). Eredu horiek faktore ezberdinak hartzen dituzte kontuan modeloetan itsas hondakinen iturriak irudikatzeko, hala nola 
kostaldeko populazio-dentsitatea, urbanizaturiko arroen proportzioa eta itsas flota-dentsitatea; eta kostaldearen geografia eta itsas korronteak kontuan izanik, MPen banaketa munduko ozeanoetan simulatzen dute.

Thompson eta lankideek [27], Eskoziako iparraldeko azaleko uretan denborarekiko aldaketak aztertzeko etengabeko plankton-grabagailuak jasotako laginen bitartez, MPen kopuruaren handitze nabarmena erakutsi zuten, 1960 ko eta 1970 eko hamarkadetako datuak 1980ko eta 1990eko hamarkadetakoekin konparatuz. Hala ere, zenbait ikerketak erakusten dute monitorizazioak emaniko MP kopuruak ez direla espero zitekeen bezain altuak; horrek aditzera eman dezake itsas hondoan pilaketa gertatzen ari litzatekeela [12, 13, 20]. Bai Woodall eta lankideek [12] bai Sánchez-Vidal eta lankideek [13] 42 eta $3500 \mathrm{~m}$ bitarteko sakoneretako itsas sedimentuetan eginiko ikerketen arabera, mikrozuntzek osatzen dute frakzio nagusia, emaitza-tarte aldakor batean (4. taula).

4. taula. MP kopurua itsas sedimentuetan, munduan zehar (MPs/50 ml sedimentuko) $[12,13]$.

\begin{tabular}{lc}
\hline \multicolumn{1}{c}{ Kokalekua } & $\begin{array}{c}\text { MP kopurua 50 ml } \\
\text { sedimentuko }\end{array}$ \\
\hline Ipar Atlantiko Subpolarra & $10-15$ \\
Ipar-ekialde Atlantikoa & $5-40$ \\
Mediterraneoa & $0-35$ \\
Hego-mendebalde Indiakoa & $1,4-4$ \\
\hline
\end{tabular}

Hondartzetako sedimentuei dagokienez, Browne eta lankideek [32] sei kontinentetako 18 hondartza aztertu zituzten, eta MP kopuru altuenak populazio altuko aldeetan aurkitu zituzten. Garbitegietako ur-hondakinetatik eratorritako zuntzak identifikatu zituzten MP iturri nagusienetarikotzat. Lagineko MP kopurua, 2 (Australia) eta 31 (Portugal, Erresuma Batua) item artean egongo litzateke $250 \mathrm{ml}$ sedimentuko, $1 \mathrm{~mm}$ baino tamaina txikiagoa duten partikulei dagokienez.

\section{ONDORIOAK ETA GOGOETA}

Orain hasi gara begietara ikusezina denaz kontzientzia hartzen. Literaturan aurkitu den lan kopuruak, batez ere azken hamarkadan, MPek ingurumenean duten presentzia eta inpaktuagatik hartu duten interesa eta garrantzia azpimarratzen du. Komunitate zientifikoak eta ingurumen-agintariek MPen definizioa zehaztu dute azken urteetan: $5 \mathrm{~mm}$ baino txikiagoak diren partikulek osatzen dute. Hainbat ikerketa-lanek MPen jatorria aztertzea 
izan dute helburu. 'MP primarioak' eskalan ekoizten dira, hala nola pelletak edota mikroesferak. 'MP sekundarioak', berriz, plastiko handiagoek jasandako degradazioaren ondorioz sortu direnek osatzen dituzte. Horien guztien sorburua eta garraioak aztertu dira. Estoldak eta ibaiak dira MP primarioen garraio-bide nagusia. Ehun-gaiak garbitzean askaturiko zuntzek osatzen dute, bestalde, MP sekundarioen iturri nagusienetariko bat, zeinek itsasora jotzen baitute ur-hondakinen araztegietatik edo ibaien bitartez. Itsasoko iturrietatik sortutako MPek ere frakzio garrantzitsua osatzen dute [21]. Aldiz, ikusi da hondakin plastikoak, behin itsasoan pilatuta daudenean, nagusiki hondartzetan degradatzen direla.

Behin MPak itsas ingurunera iritsita, horien dinamikak ez dio makrohondakinenari jarraitzen. Korronteek eta haizeek eragina dute, baina MPen dentsitateak eta barreiatze-gaitasunak ere zeresana dute. Aipatutako dentsitateak berebiziko garrantzia dauka MPak izango dituen mugimenduetan: arinenak ur-azalean ibiliko dira, eta astunenak, berriz, hondoan pilatuko dira. Baina MPak itsaso-bizitzaren substratu ere badira, biofilma osatu eta, dentsitatea aldatzean, hondora daitezke. Horrela, MPen ezaugarrien arabera, ingurumen-konpartimentuetan, talde nagusietan banatzen dira. Itsasokonpartimentu guztietan topatu dira MPak: ur-azalean, sedimentuetan (itsas hondoan, hondartzetan eta kostan, oro har) eta biotan. MP kantitateak, nabarmenki, behatutako konpartimentuaren, neurketa-teknikaren, eremu geografikoaren eta neurketa momentuaren arabera aldatzen dira; horrek MPen presentziak aldakortasun handia duela frogatzen du. Konpartimentuaren araberako laginketa-metodologia adostu baten gabeziak itsasoen arteko egoeraren konparaketa zailtzen du. Ur-azaleko MPen mugimenduak eta kontzentrazio-ereduak proposatu dira, laginketa esperimentalekin balioztatu direnak. Simulazioek erakutsi dute itsas hondakinak (MPak barne) ur-azalean giro, itsas erreketan, itsaso itxietan (Mediterraneoa) eta itsas sarguneetan edo golkoetan pilatzen direla. Itsas hondoetako sedimentuetan, berriz, ibaien lumak eta itsas arroilak garraio-bide nagusiak direla uste da [13, 54]. Hondartzetan eta kostan, bertan sortutako MPak eta itsas korronteek ekarritako MP arinak pilatzen dira. Azkenik, biotak elikagai gisa xurgatutako MPak ere kate trofiko guztian dauden itsas bizitza mota desberdinetan atzeman dira [14]. Biodibertsitatean duten ingurumen-arriskuaz gain, giza osasunarentzat izan dezaketen arriskua ere aztertzeko hainbat ikerketa garatzen ari dira [5].

Lan asko dago egiteko, baina arazoari heltzen hasi gara. Egindako lana sakondu beharra dago: laginak jasotzeko eta aztertzeko metodologia adostu, mundu-mailako monitorizazio-programak ezarri, MP sekundarioen degradazio-mekanismoetan sakondu eta konpartimentuen arteko dinamika aztertu. Era berean, MPek ingurumenean dituzten inpaktuak eta giza osasunarentzat dakartzaten arriskuak zehaztu behar dira. Administrazio batzuk hasi dira legedi eta plastikoen erabilera-araudi berrietan MPen sorkuntza murrizteko neurriak proposatzen. Arrisku-ebaluazio metodologiak garatzen 
ari dira, bizitza-zikloaren azterketetan eta ingurumenean duten inpaktuetan arreta ipiniz. Gizartea ere kontzientzia hartzen hasi da; horrek gaur egungo erabilera bakarreko produktuen ohiturak aldatzen lagunduko du. Zaila da, ia ezinezkoa, itsas ingurunea MPetatik garbitzea. Egindako kaltea eginda dago, baina ez areagotzea gure esku dago.

\section{ESKER ONAK}

Ikerlariek, Gipuzkoako Foru Aldundiko Ingurumena eta Obra Hidraulikoak Departamentua eskertu nahi lukete, ITSASMIKRO proiektuaren bitarteko laguntzagatik, baita EHU/UPV ere, GIU 18/216 proiektuaren bitarteko laguntzagatik.

\section{BIBLIOGRAFIA}

[1] PlasticsEurope. 2018. Plastics - the facts 2018. PlasticsEurope, Brussels.

[2] GESAMP. 2015. Sources, fate and effects of microplastics in the marine environment: A global assessment (Kershaw, P. J., ed.). GESAMP, London.

[3] Directive (EU) 2019/904 of the European Parliament and of the Council of 5 June 2019 on the reduction of the impact of certain plastic products on the environment. DOUE, 155, june 2019, 1-19.

[4] UNEP. 2016. Marine plastic debris and microplastics - Global lessons and research to inspire action and guide policy change. United Nations Environment Programme, Nairobi.

[5] SAPEA, Science Advice for Policy by European Academies. 2019. A scientific perspective on microplastics in nature and society. SAPEA, Berlin.

[6] ARTHUR, C., BAKER, J., BAMFORD, H. (eds.) 2009. Proceedings of the international research workshop on the occurrence, effects and fate of microplastic marine debris. Sept 9-11, 2008. NOAA National Oceanic and Atmospheric Administration. Tacoma.

[7] THOMPSON, R.C. 2015. «Microplastics in the marine environment: Sources, consequences and solutions». Marine anthropogenic litter (pp. 185-200).

[8] Directive 2008/56/EC of the European Parliament and of the Council of 17 June 2008 establishing a framework for community action in the field of marine environmental policy (Marine Strategy Framework Directive). DOUE 125 , may 2017, 27-33.

[9] FRIAS et al. 2018. Standardised protocol for monitoring microplastics in sediments. JPI-oceans BASEMAN Project.

[10] RYAN, P.G., MOORE, C.J., VAN FRANEKER, J.A., eta MOLONEY, C.L. 2009. «Monitoring the abundance of plastic debris in the marine environment». Philosophical Transactions of the Royal Society B: Biological Sciences, 364(1526), 1999-2012. 
[11] BARNES, D.K., GALGANI, F., THOMPSON, R.C., eta BARLAZ, M. 2009. «Accumulation and fragmentation of plastic debris in global environments». Philosophical Transactions of the Royal Society B: Biological Sciences, 364(1526), 1985-1998.

[12] WOODALL, L.C., SANCHEZ-VIDAL, A., CANALS, M., PATERSON, G.L., COPPOCK, R., SLEIGHT, V. et al. 2014. «The deep sea is a major sink for microplastic debris». Royal Society Open Science, 1(4), 140317.

[13] SANCHEZ-VIDAL, A., THOMPSON, R.C., CANALS, M., eta DE HAAN, W.P. 2018. «The imprint of microfibres in southern European deep seas». PloS One, 13(11), e0207033.

[14] LUSHER, A. 2015. «Microplastics in the marine environment: Distribution, interactions and effects». Marine anthropogenic litter (pp. 245-307).

[15] SCHWABL, P., LIEBMANN, B., KOPPEL, S., KONIGSHOFER, P., BUCSICS, T., TRAUNER, M., REIBERGER, T. 2018. «Assessment of microplastic concentrations in human stool-Preliminary results of a prospective study». United European Gastroenterol J, 2018, 6, p. A127.

[16] Global plastic production from 1950 to 2017 (in million metric tons) https:// Www.statista.com/statistics/282732/global-production-of-plastics-since1950/. 2019, urtarrilak 30.

[17] AUTA, H.S., EMENIKE, C.U., eta FAUZIAH, S.H. 2017. «Distribution and importance of microplastics in the marine environment: A review of the sources, fate, effects, and potential solutions». Environment International, 102, 165-176. doi:10.1016/j.envint.2017.02.013

[18] OSPAR Commission. 2017. Assessment document of land-based inputs of microplastics in the marine environment. OSPAR Commission, London.

[19] ANDRADY, A.L. 2011. «Microplastics in the marine environment». Marine Pollution Bulletin, 62(8), 1596-1605. doi:10.1016/j.marpolbul.2011.05.030

[20] SHERRINGTON C. 2016. «Plastics in the marine environment». Eunomia research and consulting ltd, p.13.

[21] ERIKSEN, M., LEBRETON, L.C.M., CARSON, H.S., THIEL, M., MOORE, C.J., BORERRO, J.C. et al. 2014. «Plastic pollution in the world's oceans: More than 5 trillion plastic pieces weighing over 250,000 tons afloat at sea». PLoS One, 9(12), e111913. doi:10.1371/journal.pone.0111913

[22] JAMBECK, J.R., GEYER, R., WILCOX, C., SIEGLER, T.R., PERRYMAN, M., ANDRADY, A. et al. 2015. «Marine pollution. Plastic waste inputs from land into the ocean». Science (New York, N.Y.), 347(6223), 768.

[23] THOMPSON, R.C. 2006. «Plastic debris in the marine environment: Consequences and solutions». In: Krause, J.C., Nordheim, H., Bräger, S. (eds.), Marine nature conservation in Europe. Federal agency for nature conservation, Stralsund, Germany, pp. 107-115.

[24] SCHMIDT, C., KRAUTH, T., eta WAGNER, S. 2017. «Export of plastic debris by rivers into the sea». Environmental Science \& Technology, 51(21), 12246-12253. 
[25] HIDAlGO-RUZ, V., GUTOW, L., THOMPSON, R.C., eta THIEL, M. 2012. «Microplastics in the marine environment: A review of the methods used for identification and quantification». Environmental Science \& Technology, 46(6), 3060-3075.

[26] GALGANI, F., HANKE, G., eta MAES, T. 2015. «Global distribution, composition and abundance of marine litter». Marine anthropogenic litter (pp. 29-56).

[27] THOMPSON, R.C., OLSEN, Y., MITCHELL, R.P., DAVIS, A., ROWLAND, S.J., JOHN, A.W. et al. 2004. «Lost at sea: Where is all the plastic?». Science, 304(5672), 838.

[28] CARPENTER, E.J., ANDERSON, S.J., HARVEY, G.R., MIKLAS, H.P., eta PECK, B.B. 1972. «Polystyrene spherules in coastal waters». Science, 178(4062), 749-750.

[29] COLE, M., LINDEQUE, P., HALSBAND, C., eta GALLOWAY, T.S. 2011. «Microplastics as contaminants in the marine environment: A review». $M a$ rine Pollution Bulletin, 62(12), 2588-2597. doi:10.1016/j.marpolbul.2011. 09.025

[30] KAZOUR, M., TERKI, S., RABHI, K., JEMAA, S., KHALAF, G., AMARA, R. 2018. «Sources of microplastics pollution into the marine environment: importance of wastewater treatment plant and coastal dump». MICRO 2018 international conference. Lanzarote, Spain, 19-23 November.

[31] TALVITIE, J., MIKOLA, A., KOISTINEN, A., eta SETÄLÄ, O. 2017. «Solutions to microplastic pollution-Removal of microplastics from wastewater effluent with advanced wastewater treatment technologies». Water Research, 123, 401-407.

[32] BROWNE, M.A., CRUMP, P., NIVEN, S.J., TEUTEN, E., TONKIN, A., GALLOWAY, T. et al. 2011. «Accumulation of microplastic on shorelines worldwide: Sources and sinks». Environmental Science \& Technology, 45(21), 9175-9179.

[33] NAPPER, I.E., eta THOMPSON, R.C. 2016. «Release of synthetic microplastic plastic fibres from domestic washing machines: Effects of fabric type and washing conditions». Marine Pollution Bulletin, 112(1-2), 39-45.

[34] ANDRADY, A.L. 2015. «Persistence of plastic litter in the oceans». Marine anthropogenic litter (pp. 57-72).

[35] ANDRADY, A.L. 2003. Plastics and the environment John Wiley \& Sons, New Jersey.

[36] KEDZIERSKI, M., D'ALMEIDA, M., MAGUERESSE, A., LE GRAND, A., DUVAL, H., CÉSAR, G. et al. 2018. «Threat of plastic ageing in marine environment. Adsorption/desorption of micropollutants». Marine Pollution Bulletin, 127, 684-694. doi:10.1016/j.marpolbul.2017.12.059

[37] LAMBERT, S., eta WAGNER, M. 2016. «Formation of microscopic particles during the degradation of different polymers». Chemosphere. 161, 510-517.

[38] TER HALlE, A., LADIRAT, L., MARTIGNAC, M., MiNGOTAUD, A.F., BOYRON, O., eta PEREZ, E. 2017. «To what extent are microplastics from 
the open ocean weathered?» Environmental Pollution, 227, 167-174.. doi:// doi.org/10.1016/j.

[39] SONG, Y.K., HONG, S.H., JANG, M., HAN, G.M., JUNG, S.W., eta SHIM, W.J. 2018. «Combined effects of UV exposure duration and mechanical abrasion on microplastic fragmentation by polymer type». Environmental Science \& Technology, 52(6), 3831-3832. doi:10.1021/acs.est.8b00172

[40] GALGANI, F., HANKE, G.,WERNER, S., OOSTERBAAN, L., NILSSON, P., FLEET, D., KINSEY, S., THOMPSON, R.C., VAN FRANEKER, J., VLACHOGIANNI, T., SCOULLOS, M., VEIGA, J.M., PALATINUS, A., MATIDDI, M., MAES, T., KORPINEN, S., BUDZIAK, A., LESLIE, H., GAGO, J., LIEBEZEIT, G. 2013. Guidance on monitoring of marine litter in European seas. MSFD GES Technical Subgroup on Marine Litter (TSG-ML), Joint Research Centre of the European Commission, Luxembourg.

[41] WRIGHT, S.L., THOMPSON, R.C., eta GALLOWAY, T.S. 2013. «The physical impacts of microplastics on marine organisms: A review». Environmental Pollution, 178, 483-492.

[42] GAGO, J., HENRY, M., eta GALGANI, F. 2015. «First observation on neustonic plastics in waters off NW Spain (spring 2013 and 2014)». Marine Environmental Research, 111, 27-33.

[43] FRÈRE, L., PAUL-PONT, I., RINNERT, E., PETTON, S., JAFFRÉ, J., BIHANNIC, I., HUVET, A. 2017. «Influence of environmental and anthropogenic factors on the composition, concentration and spatial distribution of microplastics: A case study of the Bay of Brest (Brittany, France)». Environmental Pollution, 225, 211-222.

[44] VAN SEBILlE, E., WILCOX, C., LEBRETON, L., MAXIMENKO, N., HARDESTY, B.D., VAN FRANEKER, J.A. et al. 2015. «A global inventory of small floating plastic debris». Environmental Research Letters, 10(12), 124006.

[45] MAXIMENKO, N., HAFNER, J., eta NIILER, P. 2012. «Pathways of marine debris derived from trajectories of Lagrangian drifters». Marine Pollution Bulletin, 65(1-3), 51-62.

[46] LEBRETON, L., GREER, S.D., eta BORRERO, J.C. 2012. «Numerical modelling of floating debris in the world's oceans». Marine Pollution Bulletin, 64(3), 653-661.

[47] ANDRADY, A.L. 2017. «The plastic in microplastics: A review». Marine Pollution Bulletin, 119(1), 12-22.

[48] TEUTEN, E.L., SAQUING, J.M., KNAPPE, D.R., BARLAZ, M.A., JONSSON, S., BJÖRN, A. et al. 2009. «Transport and release of chemicals from plastics to the environment and to wildlife». Philosophical Transactions of the Royal Society B: Biological Sciences, 364(1526), 2027-2045.

[49] LATTIN, G.L., MOORE, C.J., ZELLERS, A.F., MOORE, S.L., eta WEISBERG, S.B. 2004. «A comparison of neustonic plastic and zooplankton at different depths near the southern California shore». Marine Pollution Bulletin, 49(4), 291-294. 
[50] OBBARD, R.W., SADRI, S., WONG, Y.Q., KHITUN, A.A., BAKER, I., eta THOMPSON, R.C. 2014. «Global warming releases microplastic legacy frozen in arctic sea ice». Earth's Future, 2(6), 315-320.

[51] SADRI, S.S., eta THOMPSON, R.C. 2014. «On the quantity and composition of floating plastic debris entering and leaving the Tamar estuary, southwest England». Marine Pollution Bulletin, 81(1), 55-60.

[52] Impacts of MicroPlastics in AgroSystems and Stream Environment, IMPASSE Project, NIVA Norwegian Institue of Water Research, www.niva.no/ en/projectweb/impasse. 2019, apirilak 23.

[53] LÖDER, M.G., eta GERDTS, G. (2015). «Methodology used for the detection and identification of microplastics-A critical appraisal». Marine anthropogenic litter (pp. 201-227).

[54] GALGANI, F., LEAUTE, J.P., MOGUEDET, P., SOUPLET, A., VERIN, Y., CARPENTIER, A. et al. 2000. «Litter on the sea floor along European coasts». Marine Pollution Bulletin, 40(6), 516-527. Doi: 10.1016/S0025326X(99)00234-9 